\title{
TRAINING
}

\section{The role of distance learning in specialist medical training}

\author{
H Davies, D M B Hall, V Harpin, C Pullan
}

Arch Dis Child 2005;90:279-283. doi: 10.1136/adc.2003.048835

The Quality Assurance Agency for Higher Education (QAA) defines distance learning (DL) as "a way of providing higher education that involves the transfer to the student's location of the materials that form the main basis of study, rather than the student moving to the location of the resource provider".

See end of article for authors' affiliations

.....................

Correspondence to: Prof. D M Hall, Institute of General Practice, Community Sciences Building, Northern General' Hospital, Sheffield S5 7AU, UK; d.hall@ sheffield.ac.uk

Accepted 30 July 2004
D istance learning is a way of offering education and learning to students remote from major centres. It often makes use of emerging technologies, although some highly successful models are entirely paper based. ${ }^{2}$ The QAA Guidelines emphasise rigorous quality assurance and identify four dimensions within systems of distance learning (see box 1).

Although there are many reports in the literature of DL projects, experience is still limited in the provision of DL for doctors undertaking specialty training in the $\mathrm{UK}^{3-5} \mathrm{In}$ this paper we report on what we have learnt about the practical aspects and difficulties of running a DL course, developed primarily for specialist registrars* in paediatrics. Our course offers an intensive educational programme in childhood disability, but the issues addressed are probably relevant to trainees in many other disciplines.

\section{THE CONTEXT}

The current increased emphasis on better formal education for doctors in training dates from 1996, when the UK system of medical postgraduate specialist training was transformed with the introduction of the Calman plan. This resulted in a substantially reduced duration of training and coincided with a progressive reduction in working hours. Continuity of care has inevitably suffered and doctors in training now have reduced opportunities for gathering clinical experience with non-acute and long term disorders which evolve over months or years, as well days or a few weeks.

It is now more important than ever to get the maximum learning from each clinical situation in order to acquire competence and excellence as quickly as possible. Trainees also need to understand the relevance of basic sciences and research findings to the cases they are seeing each day. The explosion of knowledge and the volume of relevant work that now emerges from disciplines

* In the UK an SpR (specialist registrar) embarking on this course would normally have completed at least four years of general paediatric training. as in the care of acute illness episodes lasting other than one's own clinical field mean that all professionals must be competent in searching information resources and in the critical reading and application of research papers.

\section{WHY DISTANCE LEARNING?}

DL has several advantages over traditional courses. It can resolve the dilemma of how to provide high quality education in subjects where the number of potential participants is small and they are widely scattered. A traditional taught course delivered in a single location is economical in terms of course development and tutor input but is often incompatible with the changing lifestyles of professionals and this limits participation. An increasingly large proportion of the medical workforce, particularly in paediatrics, is female. Family and domestic commitments make it difficult for doctors to attend taught courses that require them to reside away from home for lengthy periods at a university centre. Distance learning reduces travel and accommodation costs and enables trainees to maximise local clinical experience, including maintaining their on-call commitments.

A further advantage is that DL can enable participants to continue in and learn from their clinical duties. The primary aim is to raise clinical standards by producing better informed and more reflective clinicians. The flexibility associated with DL allows each trainee to consider relevant aspects of the science, research, and management issues associated with their specialty in relation to real everyday problems.

\section{NATURE OF THE DISTANCE LEARNING PROGRAMME}

A review of the literature and other DL courses, ${ }^{6}$ and conversations with potential participants, suggested that certain features would be essential for the success of a DL course for SpRs:

- A clearly defined programme of study relevant to the clinical and managerial realities of the modern NHS

- A syllabus based on the scope of the subject as set out by the appropriate professional bodies $^{* *}$ and supported by them

- Supply of all essential study materials to minimise the need for frequent visits to medical libraries or purchasing reprints online

** In the case of our course, these were the British Association of Community Child Health (BACCH); European Academy of Childhood Disability; British Paediatric Neurology Association; and Standing Committee on Disability of the Royal College of Paediatrics and Child Health (RCPCH). 
Box 1: Four dimensions within systems of distance learning

- Materials-based learning. Learning resource materials made available to students studying at a distance. Includes printed, audio or audiovisual material, experimental equipment, and material on the world wide web and other electronic or computer based resources, distributed by travelling teachers, by post or electronic communication, or personal collection.

- Programme components delivered by travelling teachers. Staff travelling on a periodic basis to the location of the student to deliver components of the programme, via intensive classroom based study or with an individual student.

- Learning supported locally. Includes administrative tasks for which a local agent is contracted and/or specified teaching functions for which a local tutor is engaged. May include residential workshops.

- Learning supported from the providing institution remotely from the student. A tutor from the providing institution may support students individually or in groups by print, audio or video cassette, telephone, fax, email, and the internet.

- Support for the learner that would be locally accessible and not time consuming

- Use of email for communications and submission of assignments

- Realistic in terms of the demands made on the learner

- Using a variety of educational methods

- Incorporating methods of assessment that are relevant to the course objectives and achievable within limited resources.

\section{CREATING THE COURSE}

A business proposal was prepared and a grant to cover startup costs and subsidise the first cohort was obtained from the Department of Health. The support of the Chief Executive of the Sheffield Children's Hospital was enlisted and the course was approved as an official activity of the Postgraduate Centre, thus giving it a legal home. A small working group was established. A paediatrician (CP) was appointed with

\section{Box 2: Structure of the course}

- Unit 1: Introduction to disability

- Unit 2: Working with families

- Unit 3: The statutory services network

- Unit 4: Epilepsy and funny turns

- Unit 5: Cerebral palsies

- Unit 6: Motor disorders

- Unit 7: Learning disabilities

- Unit 8: Specific learning disorders, DCD, ADHD

- Unit 9: Communication disorders

- Unit 10: Hearing and vision

- Unit 11: Wider aspects of disability

- Unit 12: Links sufficient time to commit an average of 15 hours per week to the project during the development phase.

\section{STRUCTURE AND CONTENT OF THE COURSE}

\section{A 12 unit structure}

The course was planned as a two year programme, with two months allocated to each of 12 units (see box 2). Desired educational outcomes were initially somewhat non-specific but have been steadily refined as the course develops. A study guide for each unit was planned by the group; these were developed primarily by one of us (CP), using material provided by subject experts. The guides provide a framework which steers the student through the work required of them and contain several types of material. ${ }^{7}$ There are sections that introduce a topic and pose questions for consideration and reflection by the student, followed by quotations from experts and suggested solutions or answers. A core text, extensive background papers, and some clinical video material are supplied; the student is advised when to study these and is then invited to summarise key messages or reflect on the relevance of the material to their own practice. Various tasks are required of the student; for example, reports on visits to a particular specialist unit or a reflection on a difficult issue related to a patient. The student is also required to conduct or participate in an audit, undertake a literature review on a topic of their choice, and prepare a patient/parent information leaflet.

The course requires around five hours of study per week in addition to the local visits suggested by the course units and the clinical opportunities already available to the student which can be used for acquiring experience, reflecting on, and applying what has been learnt. In total this amounts to around 10 hours of "contact time" per week. When combined with the three tasks outlined above and four residential sessions (see below), the total time involved is approximately 1200 hours over two years.

\section{Copyright issues}

It is important to comply with copyright law when creating any new course in which reading material is supplied to students. In our course we supply around 240 papers and reports. In order to eliminate expensive photocopying and postage we converted all the material into PDF files. We chose to present this on a CD rather than on the web. Most students print the material from the $\mathrm{CD}$ rather than reading it on screen so that they can take it with them to use in different places and are not tied to the computer. There are recognised procedures for obtaining copyright permissions for DL courses using paper copies, ${ }^{8}$ but the legal position and licensing arrangements are still being clarified with regard to electronic copying, whether on the web or on CD. This matter is ongoing but it is believed that it will be resolved soon.

\section{Student contact and residential sessions}

Contact between course leaders, tutors, and students, and submission of assignments, are managed by email, but our internet discussion group has not proved popular with many students. Electronic communication, though vital, is no substitute for personal contact. Social and academic support networks are very important for distance learning, and some topics can best be taught by a face-to-face approach. Accordingly, four three-day residential sessions are included during the two years. These are used for dealing with issues such as use of the internet, consultation skills, child assessment, conversing with children and young people who need specialised means of communication, looking at aids and equipment, discussing topics with relevant experts, and dealing with bereavement, child protection, and other difficult situations. Some of this work is done using role play. 
The residential sessions allow the students to share their experiences and provides an opportunity for the course leaders to obtain feedback from them as to how the course is progressing, what difficulties have arisen, new ideas, etc.

\section{Recruitment of students}

When they apply to join the course, students are asked to confirm that they have the support of their educational supervisor (or line manager if not in a training post) in undertaking the course, and to say what sort of support they might obtain locally. They are also asked to describe their current job since they must have access to clinical learning opportunities-a purely theoretical approach to this course is not feasible. Students must confirm that they will have internet and email access for the duration of the course.

For the first course, we advertised extensively and had over 130 applications. We accepted 20 students as a good number for interaction at the residential sessions. This has proved to be about right in terms of our resources and student interaction, and about 20 have been recruited in each of the four years since the course began. Currently, all the students are either SpRs or hold career posts in paediatrics.

For the first cohort we aimed to recruit the most able and enthusiastic students, who would learn fast and help us to refine the course. Since the aim of this course is primarily to improve patient care, we now believe it is important to include a range of students and to offer all clinicians the same opportunity to improve their clinical practice. This is in contrast to the policy of most University Masters programmes.

\section{The role of tutors}

Each student is assigned a personal tutor, usually a consultant paediatrician who works in the same area and has some knowledge of the local situation. Initially, the tutor played an essentially passive role, being available to respond to requests for help from the student. It was found that many students never initiated such a contact, so the approach was changed and students are now expected to meet with their tutor at least once during each unit to review their work. The tutors are asked to report back to the course leaders whether the student is keeping up with the work and the tasks set in each unit, and to complete a brief feedback form at the end of each unit, confirming that the material is being covered adequately.

So far, tutors have been very willing to take on this role without remuneration. They are supplied with all the materials and many report that they regard their tutoring role as excellent continuing medical education for themselves. Tutors are fully briefed but formal training sessions have so far been limited. More tutors are always needed, particularly in more sparsely populated parts of the country, and a new tutor has to be found if a student moves from one part of the country to another.

\section{Assessment}

Students are required to complete an assignment for each of the 12 units. Their purpose is to show to the course supervisors that the student has in fact covered an aspect of the work that has been set out as part of the unit. The assignments are designed to be practical exercises which will directly help the students in their current and future work. Marking guidelines are produced for each assignment and are available for the students as well as the markers. Each assignment is checked both by a tutor and by one of the course supervisors, and wide discrepancies in the marking (which are unusual) are adjudicated by another course supervisor. The student is given feedback with the markers' comments going to them. The student is only asked to resubmit the work if it is felt to fall substantially below the required standard.

Most students aim for an unnecessarily high standard and we have had to emphasise that assignments should be short and do not have to be perfect. All students have difficulty in doing the coursework in addition to a full time job. Students need dedicated study time during the working week but this is very difficult for some. We have therefore had to take a more realistic view of the amount of work that can be covered during the programme and have resisted the temptation constantly to add new material.

In spite of this, some students are late in submitting their assignments. Wherever possible, students are helped to complete their assignment and they can submit them up to two months late. Clear rules are needed for students who still cannot manage to keep up. They may defer some of their assignments until the next year, to be marked with the following cohort, in which case they would complete their programme a year late. The main difficulty with this kind of flexibility is the additional administrative time required. Students are also able to drop back to another cohort if they are behind with all the material or if they need a break for personal reasons.

\section{Response to feedback and new publications}

The units have been revised for each new cohort to take account of feedback from the students and tutors. When new research appears, we remove outdated papers and substitute new ones rather than simply increase the volume of material. In future, each of the units will have a unit editor whose job will be to monitor the content, be aware of important advances in the field, commission revisions of work where required, and generally ensure that the units are kept up to date.

\section{Financial and academic sustainability}

DL is not a cheap option. We were able to write off most of the early development costs in view of the initial grant. The fees charged for our course are similar to those for university postgraduate diplomas, but even so our course is only breaking even due to the generous unpaid contributions of many colleagues.

A guarantee of stability and continuity over a number of years is important for academic recognition, for financial security, and for the general credibility of the process. Sheffield Children's NHS Trust has accepted financial responsibility for the course. The creation of a management board which includes a number of past and present tutors has helped to give an assurance that the course would not collapse if one or two key people were no longer available. An external panel of four advisers (three academics and one from a patient organisation) was also asked to offer an independent view of progress.

\section{Academic recognition}

This course has recently undergone an external appraisal by a university accreditation panel and has now been recognised as a Postgraduate Diploma, with an option to convert to a Masters' programme by the addition of a research methods course and a dissertation.

\section{HOW DO WE MEASURE SUCCESS?}

To date, four cohorts of 20 students each have entered the programme. The attrition rate has been on average two or three students per course, usually at an early stage. We cannot yet assess the overall completion rate because many students are submitting assignments with a later cohort (see above). Although there are no standards with which this can be compared directly, anecdotal evidence from others who have run distance learning programmes, for example with 
the Open University, suggests that our attrition rate is lower than expected and is indicative of a satisfactory course. Feedback from students has been overwhelmingly positive, though, by request, often laced with specific criticisms and constructive suggestions. The course is recommended by the RCPCH Specialty Committee and is said to be regarded favourably by consultant appointment panels. Some of those who have passed through the course as students are now offering their services as tutors.

\section{DISCUSSION}

It has taken five years to establish the Sheffield DL course in childhood disability. We have shown that it is possible to provide education in this way for doctors in training and that some doctors in career posts also find it valuable. We hope that the lessons learned (box 3 ) will be helpful to others who may wish to develop similar courses.

There is growing enthusiasm for web based learning, but when we started planning the course we decided against this for two main reasons-the high cost of building and

\section{Box 3: Points to consider: planning DL for} doctors in training

- Creating a DL course is more complex, more time consuming, and more expensive than a traditional taught course

- Make sure colleagues within the discipline, individually and collectively, support the need for and design of the proposed DL course

- A critical mass of committed enthusiasts is needed to prepare the course and ensure its sustainability

- Establish a legal home, liability cover, and a mechanism to deal with complaints and appeals

- Make an early decision about whether accreditation will be sought from the start or only when the course has proved itself

- Be explicit about the aims of the course and its intended market

- Define the desired learning outcomes and how they relate to assessments

- Spend a lot of time on designing and standardising assessment methods

- Use technology because it helps, not because it is available

- Be realistic in the time and workload demands placed on the learners

- Specify in detail how you will handle late delivery of assignments and assessment tasks

- Ensure students can search and analyse the literature, but provide essential reading materials and don't expect students to waste their time hunting these in the library

- Be up to date with copyright law

- Calculate the administrative time required for recruitment, enrolment, feedback etc. This will need more time during setting up than to run an established course

- Recruit tutors early, explain in detail what is expected of them, monitor their performance, and acknowledge their contribution

- Plan how the course is to be updated in response to feedback and new knowledge sustaining the multi-skilled team needed in relation to a relatively small market, ${ }^{6}$ and the variable access of participants to the internet when working at home. Access and IT literacy are increasing rapidly, but the cost of creating and servicing web resources is still an obstacle. The educational quality of DL courses may be more important than the precise method of delivery. ${ }^{9}$

Some authorities use the term "open learning" rather than distance learning, to encompass the goals of lifelong self directed learning and multidisciplinary networks. ${ }^{10}$ There is an undoubted tension between the need to help the student build a robust knowledge base (which is a prerequisite of all professional activity) and the importance of developing critical reading and reflective practice. The ultimate goal is to improve clinical care and outcomes. Only a few DL programmes have been able to show these, ${ }^{11-13}$ but studies on continuing professional development suggest that methods which are clinically based, incorporate reflection, and facilitate a learn-work-learn sequence are more likely to improve physician behaviour and patient outcomes. ${ }^{14}{ }^{15}$

We have not yet found a viable way of measuring improvements in quality of care, so we defined our immediate aim as an improvement in clinical standards. It is important to establish an assessment strategy in pursuit of that aim, so that areas for assessment match a blueprint derived from the key learning objectives of the course. Selection of the most appropriate assessment methodology for each area of the blueprint can then be undertaken.

Written assignments are useful to assess academic insight and the ability to handle complex concepts, but do not indicate whether the student has improved their clinical performance and judgement. Other methods are being investigated to strengthen our assessment process in collaboration with the RCPCH, including review of clinical reports for patients and GPs, ${ }^{16}$ and video recorded consultations following a similar model to that developed in general practice. ${ }^{17-19}$ Assessment of portfolios to encourage reflective learning and identification of key learning points from cases may be of benefit. Workplace based assessment, ${ }^{20}{ }^{21}$ which focuses on what the students are actually doing in practice, will stimulate practice based learning. ${ }^{22}$ Assessment by expert parents and young people may complement professional assessment. ${ }^{23-25}$ Regular workplace based assessment for all clinicians is a longer term goal (see box 4 ) and would greatly simplify measuring the impact of educational interventions.

Our course has evolved and changed as a result of four years' experience and the feedback from our first three cohorts. We decided to submit the programme for university accreditation only when we were satisfied with its quality and viability. We are aware that others have adopted a different approach - to carry out a number of consultation exercises, create the course, and seek formal accreditation before launching it. We suggest that our cautious incremental

Box 4: Possible methods and tools for workplace based assessment ${ }^{26-29}$

- Multi-source feedback (peer assessment)

- Observed clinical interactions, e.g. Mini-CEX

- Portfolio assessment

- Case based discussion

- Video recordings of consultations

- Patient assessment of communication skills

- Direct observation of technical skills (DOTS)

- Assessment of OP letters 
approach may be better suited to DL courses aimed at a small and specialised market. Development costs can rarely be met in full, progress relies on goodwill and professional consensus, and the first cohorts of students play a vital role in creating a relevant, high quality course.

In the future, there may be opportunities to offer all or part of this course to other professionals. A team approach may be of interest. ${ }^{30}$ Some topics could be expanded for those with more specialised interests. Individual units could be made available when required as stand alone study courses for CPD. High quality administrative support is the key to providing such individualised DL options.

\section{ACKNOWLEDGEMENTS}

We thank the Department of Health for initial financial support; many colleagues who have supported this work by writing expert papers, tutoring, or teaching; the Child Growth Foundation for providing some video content; our external panel; Sheffield Children's NHS Trust for providing a legal home for the programme; Sheffield Hallam University for their guidance in the accreditation process; Professor Dave Woods (Cape Town) and Dr Phil Candy (NHSu) for helpful comments; and the participants who have helped shape and refine the course.

\section{Authors' affiliations}

H Davies, V Harpin, Sheffield Children's Hospital and NHS Trust, Sheffield, UK

D M B Hall, Institute of General Practice, ScHARR, University of Sheffield, UK

C Pullan, Independent Consultant Paediatrician, Nottingham, UK

Competing interests: the authors are involved in the provision of the distance learning described in this article, and $\mathrm{CP}$ receives remuneration for the time spent in course development, though the other authors do not receive remuneration

\section{REFERENCES}

1 Quality Assurance Agency for Higher Education. www.qaa.ac.uk/public/ $\mathrm{dlg} /$ intro.htm (accessed 19 May 2004).

2 Woods DL. A novel approach to perinatal HIV/AIDS training for doctors and nurses in South Africa. Southern Afr J HIV Med 2003;10:42-4.

3 Jha V, Duffy S. Ten golden rules for designing software in medical education: results from a formative evaluation of DIALOG. Med Teach 2002;24:417-21.

4 Finch R, Duffy $S$. Distance learning to support postgraduate training in obstetrics and gynaecology. Hosp Med 2002;63:233-6.

5 Watkins R, Marlow N, Conole G. Internet-mediated education in neonatal medicine: module development. Pediatr Res 2002;52:117.

6 Wong G, Greenhalgh T, Russell J, et al. Putting your course on the web: lessons from a case study and systematic literature review. Med Educ 2003;37:1020-3.
7 Laidlaw JM, Harden RM, Robertson $\sqcup$, et al. The design of distance-learning programmes and the role of content experts in their production. Med Teach 2003;25:182-7.

8 Copyright Licensing Agency Ltd. www.cla.co.uk (accessed 19 May 2004).

9 Thomson Job Impact Study. http://www.netg.com/Upload/ uk_ThomsonJoblmpactStudy.pdf, 2004.

10 The Open Learning Unit, University College, London, 2004. www.ucl.ac.uk/ openlearning/ (accessed 10 June 2004).

11 Flores R, Robles J, Burkhalter BR. Distance education with tutoring improves diarrhea case management in Guatemala. Int J Qual Health Care 2002; 14(suppl 1):47-56.

12 Harris JM, Kutob RM, Surprenant Z, et al. Can internet-based education improve physician confidence in dealing with domestic violence? Fam Med 2002;34:287-92

13 Theron G. Effect of the maternal care manual from the Perinatal Education Programme on the quality of antenatal care intrapartum care rendered by midwives. S Africa Med J 1999:89:336-42.

14 Davis D. Does CME work? An analysis of the effect of educational activities on physician performance or health care outcomes. Int J Psychiatry Med 1998;28:21-39.

15 Davies HA, Diwakar V. Learning and staying up-to-date-advice for trainees and career paediatricians. In: David T, ed. Recent advances in paediatrics. London: RSM, 2002;20:183-98.

16 Crossley G, Howe A, Newble D, et al. Sheffield Assessment Instrument for Letters (SAIL): performance assessment using outpatient letters. Med Educ 2001;35:1115-24.

17 Ram P, Grol R, Rethans J, et al. Assessment of general practitioners by video observation of communicative and medical performance in daily practice: issues of validity, reliability and feasibility. Med Educ 1999;33:447-54.

18 Hays R, Spike N, Sen Gupta T, et al. A performance assessment module for experienced general practitioners. Med Educ 2002;36:258-60.

19 Tate P. The video assessment. Practitioner 1999;243:764-6.

20 Hays R, Davies H, Beard J, et al. Selecting performance assessment methods for experienced physicians. Med Educ 2002;36:910-17.

21 Norcini JJ. Work based assessment. BMJ 2003;326:753-5.

22 Kurth RJ, Silenzio V, Irigoyen MM. Use of personal digital assistants to enhance educational evaluation in a primary care clerkship. Med Teach 2002;24:488-90

23 Cooper C, Mira M. Who should assess medical students' communication skills: their academic teachers or their patients? Med Educ 1998:32:419-21.

24 Thomson AN. Reliability of consumer assessment of communication skills in a postgraduate family practice examination. Med Educ 1994;28: 146-50.

25 Finlay IG, Stott NC, Kinnersley P. The assessment of communication skills in palliative medicine: a comparison of the scores of examiners and simulated patients. Med Educ 1995;29:424-9.

26 Archer J, Davies H. Clinical management. Where medicine meets management. On reflection. Health Services J 2004;114:26-7.

27 Lockyer J. Multisource feedback in the assessment of physician competencies. J Contin Educ Health Prof 2003;23:4-12.

28 Norcini JJ, Blank LL, Duffy FD, et al. The mini-CEX: a method for assessing clinical skills. Ann Intern Med 2003;138:476-81.

29 Wilkinson T, Challis M, Hobma S, et al. The use of portfolios for assessment of the competence and performance of doctors in practice. Med Educ 2002;36:918-24.

30 Hesketh EA, Stephen KW, Laidlaw JM, et al. Lessons learned from the development of a distance-learning programme. Med Teach 2001;23:3-8. 